Ellis B. Jensen, Donghai Zheng, Robert A. Russell, Rhonda Bassel-Duby, R.

Sanders Williams, Ann Louise Olson and G. Lynis Dohm

Am J Physiol Regulatory Integrative Comp Physiol 296:1820-1828, 2009. First published Mar 25, 2009; doi:10.1152/ajpregu.90651.2008

You might find this additional information useful...

This article cites 48 articles, 33 of which you can access free at:

http://ajpregu.physiology.org/cgi/content/full/296/6/R1820\#BIBL

Updated information and services including high-resolution figures, can be found at:

http://ajpregu.physiology.org/cgi/content/full/296/6/R1820

Additional material and information about American Journal of Physiology - Regulatory, Integrative and Comparative Physiology can be found at:

http://www.the-aps.org/publications/ajpregu

This information is current as of December 8, 2010 .

The American Journal of Physiology - Regulatory, Integrative and Comparative Physiology publishes original investigations that illuminate normal or abnormal regulation and integration of physiological mechanisms at all levels of biological organization, ranging from molecules to humans, including clinical investigations. It is published 12 times a year (monthly) by the American

Physiological Society, 9650 Rockville Pike, Bethesda MD 20814-3991. Copyright @ 2009 by the American Physiological Society. ISSN: 0363-6119, ESSN: 1522-1490. Visit our website at http://www.the-aps.org/. 


\title{
Regulation of GLUT4 expression in denervated skeletal muscle
}

\author{
Ellis B. Jensen, ${ }^{1}$ Donghai Zheng, ${ }^{2}$ Robert A. Russell, ${ }^{4}$ Rhonda Bassel-Duby, ${ }^{5}$ R. Sanders Williams, ${ }^{6}$ \\ Ann Louise Olson, ${ }^{4}$ and G. Lynis Dohm ${ }^{3}$ \\ ${ }^{1}$ Department of Biology, Viterbo University, La Crosse, Wisconsin; ${ }^{2}$ Departments of Exercise and Sport Science and \\ ${ }^{3}$ Physiology, Brody School of Medicine, East Carolina University, Greenville, North Carolina; ${ }^{4}$ Deparment of Biochemistry \\ and Molecular Biology, University of Oklahoma Health Sciences Center, Oklahoma City, Oklahoma; and ${ }^{5}$ Department \\ of Molecular Biology, University of Texas Southwestern, Dallas, Texas; and ${ }^{6}$ Duke University Medical School, \\ Durham, North Carolina
}

Submitted 20 August 2008; accepted in final form 23 March 2009

\begin{abstract}
Jensen EB, Zheng D, Russell RA, Bassel-Duby R, Williams RS, Olson AL, Dohm GL. Regulation of GLUT4 expression in denervated skeletal muscle. Am J Physiol Regul Integr Comp Physiol 296: R1820-R1828, 2009. First published March 25, 2009; doi:10.1152/ajpregu.90651.2008.-Denervation by sciatic nerve resection causes decreased muscle glucose transporter 4 (GLUT4) expression, but little is known about the signaling events that cause this decrease. Experiments were designed to test the hypothesis that decreased GLUT4 expression in denervated muscle occurs because of decreased calcium/CaMK activity, which would then lead to decreased activation of the transcription factors myocyte enhancer factor 2 (MEF2) and GLUT4 enhancer factor (GEF), which are required for normal GLUT4 expression. GLUT4 mRNA was elevated in mice expressing constitutively active CaMK isoform IV (CaMKIV) and decreased by denervation. Denervation decreased GEF binding to the promoter and the content of GEF in the nucleus, but there was no change in either MEF2 binding or MEF2 protein content. Expression of a MEF2-dependent reporter gene did not change in denervated skeletal muscle. To determine the domains of the GLUT4 promoter that respond to denervation, transgenic mice expressing the chloramphenicol acetyl transferase (CAT) reporter gene driven by different lengths of the human GLUT4 promoter were denervated. Using several different promoter/reporter gene constructs, we found that all areas of the GLUT4 promoter were truncated or missing, except for the MEF2 binding domain and the basal promoter. All of the GLUT4 promoter/CAT reporter constructs evaluated responded normally to denervation. Our data lead us to conclude that decreased CaMK activity is not the reason for decreased GLUT4 content in denervated muscle and that negative control of GLUT4 expression is not mediated through the MEF2 or GEF-binding domains. These findings indicate that withdrawal of a GEF- or MEF2dependent signal is not likely a major determinant of the denervation effect on GLUT4 expression. Thus, the response to denervation may be mediated by other elements present in the basal promoter of the GLUT4 gene.
\end{abstract}

denervation; exercise; myocyte enhancer factor 2; GLUT4 enhancer factor; glucose

THE TOTAL AMOUNT OF GLUT4 protein in a cell is important for maximal glucose transport rates. Whole body glucose disposal and GLUT4 protein levels are correlated in humans $(5,20)$, with exercise training (10-12) and aging (13). Studies in transgenic mice show that the correlation between GLUT4 and glucose homeostasis is one of cause and effect (19). Mice overexpressing GLUT4 specifically in skeletal muscle have improved whole body insulin action, more rapid glucose clear-

Address for reprint requests and other correspondence: G. Lynis Dohm, Dept. of Physiology, Brody School of Medicine, East Carolina Univ., 6N98 600 Moye Blvd., Greenville, NC 27834 (e-mail: dohmg@ecu.edu). ance from the blood, a higher rate of muscle glucose transport, and improved glucose homeostasis $(15,21,35,42,43)$. Overexpression of GLUT4 in genetically diabetic $o b / o b$ mice improved glycemic control and ameliorated diabetes $(3,7,16)$. While decreased GLUT4 content is not responsible for insulin resistance, increased GLUT4 is capable of rescuing or preventing insulin resistance, and ways to increase GLUT4 content could be used to treat type II diabetes (49). For this reason, it is very important that we learn how GLUT4 expression is regulated, so we can develop therapies for treating diabetes. Studies of how active muscle states, such as exercise, increase GLUT4 content have produced valuable information on how GLUT4 expression is regulated. Another way to gain information about GLUT4 gene expression is by studying the negative regulation of GLUT4 expression in inactive muscle states such as denervation.

Denervation by sciatic nerve resection decreases muscle GLUT4 mRNA and protein 50\% 3 to 7 days after denervation $(2,4)$. Denervation of the rat hindlimb muscles leads to a reduction in both GLUT4 content and uptake of the nonmetabolizable glucose analog, 3-OMG (29), and loss of GLUT4 content is highly correlated with a reduction in insulin-stimulated glucose uptake (4). GLUT4 protein expression in denervated tissue appears to be dependent on changes in mRNA, which are regulated by decreased transcription rates of the GLUT4 gene (18).

Expression of GLUT4 is highly dependent on the transcription factors GLUT4 enhancer factor (GEF) and myocyte enhancer factor 2 (MEF2). GEF is the binding protein for the GLUT4 promoter element, Domain I. Domain 1 is the region between $-742 \mathrm{bp}$ and $-712 \mathrm{bp}$ upstream of the GLUT4 transcription initiation site (33). The MEF2-binding site is located between -473 bp and -464 bp of the GLUT4 gene promoter (41). Domain 1 and the MEF2-binding site cooperate to support the pattern of expression that endogenous GLUT4 follows (33). Regulated and tissue-specific expression of the GLUT4 gene occurs only in tissues in which sufficient GEF and MEF2 binding activity coincide. In differentiated muscle, MEF2 is required for GLUT4 mRNA expression $(38,41)$, and in mice expressing a reporter gene controlled by the GLUT4 gene promoter, mutation of the MEF2 binding domain was shown to result in a complete lack of reporter gene expression $(6,41)$. Confirming the imperative nature of MEF2 as a regulator of GLUT4 transcription, mutation of the MEF2 binding site in $\mathrm{C} 2 \mathrm{C} 12$ cells also resulted in loss of function of the GLUT4 gene and decreased GLUT4 mRNA (22).

CaMK has been shown to be capable of activating MEF2. MEF2 proteins function in skeletal muscle as downstream 
effectors of calcium-regulated signaling pathways stimulated by motor nerve activity and its subsequent muscle contraction. In this way, MEF2 contributes to fiber-type-specific gene regulation $(47,48)$. CaMK allows MEF2 to become activated because CaMK phosphorylates inhibitory histone deacetylase (HDAC) proteins resulting in their dissociation from MEF2 and their export from the nucleus $(8,27,44)$. Little is known about GEF regulation and whether GEF responds to calciumsignaling pathways.

Experiments were designed to test the hypothesis that decreased GLUT4 expression in denervated muscle occurs because of decreased CaMK activity in the noncontracting muscle. Decreased CaMK activity would then lead to depressed transcriptional activation by MEF2 and GEF. To test the role of calcium signaling in regulation of GLUT4 expression in denervated muscle, GLUT4 mRNA was measured in muscle of wild-type mice and mice expressing constitutively active CaMKIV.

To determine how GEF and MEF2 DNA binding activity change during denervation, we performed electrophoretic mobility shift assays using oligonucleotides corresponding to their cognate binding sites. Mice that express a lac $Z$ reporter gene, expression of which is dependent on a gene promoter rich in MEF2 sequences, were also denervated to determine the ability of MEF2 to stimulate or repress gene expression in denervated muscle. To discover the responsible elements in the GLUT4 promoter, we denervated transgenic mice expressing the chloramphenicol acetyl transferase (CAT) reporter gene driven by different regions of the human GLUT4 promoter. We hypothesized that there would be no change in CAT expression after denervation in a transgenic mouse that did not have sufficient portion of the GLUT4 promoter to respond to denervation. In this study, new transgenic lines with promoter regions consisting of $895 \mathrm{bp}$ of GLUT4 promoter minus deleted regions between -712 to -526 bp or -440 to -220 bp were denervated along with a line with $730 \mathrm{bp}$ of promoter driving the expression of CAT. Each transgenic mouse line tested has different deleted portions of the GLUT4 promoter, but collectively, the mice have nearly the entire GLUT4 promoter deleted, or rendered ineffective, except for the MEF2 binding domain and the basal promoter (about $200 \mathrm{bp}$ upstream of the initiation site).

\section{MATERIALS AND METHODS}

Mice. All procedures were approved by the Institutional Animal Care and Use Committee of East Carolina University. Mice were housed with room temperature and lighting controlled $\left(20-22^{\circ} \mathrm{C}\right.$ : 12:12-h light-dark cycle) and were given food and water ad libitum. Transgenic mice were identified by PCR using primers specific for their respective transgenes. The mice expressing constitutively active CaMKIV (CaMKIV-TG) (34) have been described previously. The MEF2/reporter mice were previously studied (31) and were graciously provided by Dr. Eric Olson (University of Texas Southwestern Medical Center). Mice expressing the CAT reporter gene controlled by different regions of the hGLUT4 gene promoter (hGLUT4-CAT) were produced at the Oklahoma Health Sciences Center and have been previously described $(23,32,41)$. At the specified times after treatment, the mice were killed by $\mathrm{CO}_{2}$ asphyxiation. The background strain of all mice used in these studies was C57BL/6. Because the CaMK transgene expression is driven by the muscle creatine kinase (MCK) promoter, and because MCK is expressed at a higher level in white muscle fibers, plantaris muscle was used for RNA measure- ments in CaMK-transgenic mice. Gastrocnemius muscle was used in all other studies.

Materials. Primary antibodies were purchased from Santa Cruz (MEF2 H-300) and Abcam (GLUT4). GEF primary antibody was isolated and purified as previously described (33). Unless otherwise specified, all other reagents were purchased from Sigma Chemical (St. Louis, MO), Pierce Chemical (Rockford, IL), or Fisher Scientific (Springfield, NJ).

Denervation study. The mice were anesthetized with an intraperitoneal injection of a ketamine $(18 \mathrm{mg} / \mathrm{ml})$-xylazine $(2 \mathrm{mg} / \mathrm{ml})$ mixture $(0.05 \mathrm{ml} / 10 \mathrm{~g}$ body $\mathrm{wt})$, and their hindquarters were shaved in preparation for surgery. As described by Megeney et al. (29), a small incision was made in the posterior aspect of the hindlimb to expose the sciatic nerve at the level of the femoral trochanter. After severing the sciatic nerve, the same surgical procedure was performed to the contralateral hindlimb without resectioning of the sciatic nerve. The incision was closed with Autoclips, and the animals recovered for 3 days before tissue was harvested. The recovery of the animals was closely monitored, and there were no overt signs of animal distress or pain after denervation. Seventy-two hours after denervation, mice were killed by $\mathrm{CO}_{2}$ asphyxiation, and the harvested muscles were quick-frozen to liquid nitrogen temperature.

RNA isolation. A 10- to 100-mg sample of muscle was homogenized in $1 \mathrm{ml}$ of TRIzol reagent (Invitrogen) with $5 \times 10^{-7} \mathrm{~g} / \mathrm{ml}$ glycogen. Homogenates were treated with DNase from Qiagen (Valencia, CA). Qiagen RNeasy minicolumn isolation kits were used to isolate RNA, and RNA was quantified using the RiboGreen RNA quantitation kit (Molecular Probes, Eugene, OR).

RNase protection assays. Radiolabeled $\left(\left[\alpha-{ }^{32} \mathrm{P}\right] \mathrm{UTP}, 800 \mathrm{Ci} /\right.$ mmol) antisense RNA probes were transcribed from the pTRIGAPDH (glyceraldehyde 3-phosphate dehydrogenase)-mouse antisense control template (Ambion, Austin, TX) and the Bsu 361 linearized mouse GLUT4-CAT plasmid, p469GLUT4-CAT (32), using Ambion's T3/T7 MAXIscript in vitro transcription kit. Briefly, RNase protection assays (RPAs) were performed with the streamlined procedure of Ambion's RPA II kit, as previously described $(17,18)$. Ten micrograms total RNA per sample and ${ }^{32} \mathrm{P}$-labeled antisense probes were hybridized overnight at $45^{\circ} \mathrm{C}$. Nonhybridized RNA was digested for $1 \mathrm{~h}$ at $37^{\circ} \mathrm{C}$ with 1:1,000 dilution of RNase T1/A from RPA II kit. The protected RNA fragments were separated by using $6 \%$ acrylamide 7.5 M urea gel electrophoresis and were then exposed to PhosphorImager and quantitated with Imagequant software (Molecular Dynamics, Sunnyvale, CA). The size of the protected fragments was estimated by RNA transcripts labeled with $\left[\alpha-{ }^{32} \mathrm{P}\right] \mathrm{UTP}$ from Century Marker Templates (Ambion) by using T7 RNA polymerase. Endogenous GLUT4 and CAT measurements were normalized to GAPDH measurements. GAPDH was chosen as an appropriate normalizer for the data because of its lack of responsiveness to denervation.

Electrophoretic mobility shift assay. Electrophoretic mobility shift assays were done as described previously (33). Oligonucleotides were end-labeled with T4 polynucleotide kinase. Labeled probes $(0.5 \mathrm{ng})$ were incubated with $10 \mathrm{mg}$ of total protein isolated from nuclei in a $10-\mathrm{ml}$ reaction containing $2 \mathrm{mg}$ of poly(dI-dC), $40 \mathrm{mM} \mathrm{KCl}, 5 \mathrm{mM}$ $\mathrm{MgCl}_{2}, 15 \mathrm{mM}$ HEPES, pH 7.9, 1 mM EDTA, $0.5 \mathrm{mM}$ DTT, and 5\% glycerol for $20 \mathrm{~min}$ at room temperature. For competition studies, extracts were preincubated with various concentrations of unlabeled oligonucleotide, as indicated for $5 \mathrm{~min}$ before the addition of the radiolabeled probe. For competition studies using antibodies, extracts were preincubated with $2.5 \mathrm{mg}$ of preimmune IgG, anti-GST-MEF2 $\mathrm{IgG}$, or $\mathrm{IgG}$ from an irrelevant antiserum raised against a glutathione S-transferase (GST) fusion protein. Preincubation was carried out for $1 \mathrm{~h}$ on ice before the addition of the radiolabeled probe. Samples were electrophoresed on a nondenaturing $6 \%$ polyacrylamide gel (29:1 acrylamide:bis acrylamide) buffered with Tris borate/EDTA (TBE; 22 $\mathrm{mM}$ Tris, $22 \mathrm{mM}$ boric acid, and $0.5 \mathrm{mM}$ EDTA) at $300 \mathrm{~V}$ for $25 \mathrm{~min}$ at room temperature. Gels were dried and an exposure of them were made on film at room temperature. 
Quantitative RT-PCR. Quantitative RT-PCR (QRT-PCR) was used to analyze GLUT4 mRNA content in whole muscle samples from CaMKIV-transgenic mice, MEF2/reporter mice, and wild-type controls, according to the protocol described previously (30). After quantification of RNA, cDNA was synthesized with the reverse transcriptase reaction, using the iScript RT kit (Bio-Rad, Hercules, CA). Quantitative real-time PCR was performed using an ABI Prism 7300 Sequence Detection System instrument and software (PE Applied Biosystems, Foster City, CA). Prevalidated GLUT4 and lacZ primer/probe sets were purchased from PE Applied Biosystems. GLUT4 and lacZ mRNA values were normalized to $18 \mathrm{~s}$ rRNA to correct for slight differences in sample substrate.

Nuclear isolation. Nuclear protein was isolated from gastrocnemius muscle using the NE-PER nuclear extraction kit (NE-PER; Pierce, Rockford, IL), as previously explained (25). Briefly, muscle samples were homogenized with 15 passes of a glass-on-glass tissue homogenizer in 10 volumes of cytoplasmic extraction reagent I. Cytoplasmic extraction reagent II was added at a final concentration of 5\%, and the homogenate was spun in a centrifuge at $16,000 \mathrm{~g}$ for $5 \mathrm{~min}$. The supernatant was extracted, and the pellet was resuspended in $100 \mu \mathrm{l}$ of nuclear extraction reagent and sat on ice for $40 \mathrm{~min}$ with occasional mixing. The resuspended pellet was again spun in a centrifuge at $16,000 \mathrm{~g}$ for $10 \mathrm{~min}$, and the supernatant, representing nuclear protein, was extracted and stored.

Protein sample preparation. Powdered muscle was homogenized $(2 \times 20 \mathrm{~s})$ on ice in homogenization buffer containing $50 \mathrm{mM}$ $\mathrm{N}$-2-hydroxyethylpiperazine- $\mathrm{N}^{\prime}$-ethane (HEPES) (pH 7.4), $10 \mathrm{mM}$ EDTA, $100 \mathrm{mM} \mathrm{NaF}, 50 \mathrm{mM}$ Na pyrophosphate, $10 \mathrm{mM} \mathrm{Na}$ orthovanadate, $0.1 \mathrm{mg} / \mathrm{ml}$ aprotinin, $1 \%$ Triton, $5 \mu 1 / \mathrm{ml}$ protease inhibitor cocktail, and $10 \mu \mathrm{l} / \mathrm{ml}$ phosphatase inhibitor cocktails I and II (Pierce) with an Ultra-Turrax homogenizer (IKA, Wilmington, NC). For measurement of total protein, samples were centrifuged, after homogenization, at $15,000 \mathrm{~g}$ for $10 \mathrm{~min}$ at $4^{\circ} \mathrm{C}$. The supernatant was removed and stored on ice for protein quantitation.

For isolation of membrane-associated proteins, samples were centrifuged at $150,000 \mathrm{~g}$ for $1 \mathrm{~h}$ at $4^{\circ} \mathrm{C}$. The pellet was resuspended by homogenization $(2 \times 10 \mathrm{~s})$ on ice in homogenization buffer with an Ultra-Turrax homogenizer (IKA, Wilmington, NC). 1\% IGEPAL detergent was added, and samples were mixed by shaking at $4^{\circ} \mathrm{C}$ for $1 \mathrm{~h}$. After a second centrifugation, the supernatant (particulate fraction) was collected and stored on ice for measurement of protein content followed by Western blot analysis. All samples were measured for protein content in triplicate by bicinchoninic acid procedure.

Western blot analyses. Proteins were resolved by SDS-PAGE on $7.5 \%$ or $10 \%$ Criterion resolving gels (Bio-Rad) at $200 \mathrm{~V}$ for $1 \mathrm{~h}$ in running buffer containing $25 \mathrm{mM}$ Tris, $19.2 \mathrm{mM}$ glycine and $0.1 \%$ SDS. Samples were then transferred at $100 \mathrm{~V}$ for $2 \mathrm{~h}$ to Immobilon-P polyvinylidene difluoride membrane in transfer buffer containing 25 $\mathrm{mM}$ Tris, $19.2 \mathrm{mM}$ glycine. Membranes were then blocked with 5\% nonfat milk with $1 \%$ BSA in $10 \mathrm{mM}$ Tris-buffered saline (TBS) solution overnight at $4^{\circ} \mathrm{C}$. The membranes were incubated for $1 \mathrm{~h}$ with primary antibody at room temperature in $5 \%$ nonfat milk/TBS or $5 \%$ BSA/TBS, according to antibody manufacturer protocol. Membranes were washed $(4 \times 5 \mathrm{~min}$ in TBST $)$ and incubated with anti-rabbitHRP or anti-goat-HRP conjugated antibodies in $5 \%$ milk/TBST at room temperature for $1 \mathrm{~h}$. Membranes were incubated in Super Signal West Pico luminescence solution (Pierce), according to manufacturer protocol and exposed to film. Films were scanned using Epson Perfection 3200 negative flatbed scanner (Epson America, Long Beach, CA), and band density was quantified using GelPro Analyzer Software (Media Cybernetics, Silver Spring, MD).

Statistical analysis. For comparison of mRNA and protein content in control and denervated wild-type and transgenic mice, two-way ANOVA was used to identify statistical differences. An independent samples $t$-test was used for post hoc comparison of groups only after main effects were shown by two-way ANOVA. Results are reported as means \pm SE. Comparison of control and denervated groups were performed by paired $t$-tests. All statistical analyses were performed with Statistical Package for the Social Sciences (SPSS; v. 11.0, Chicago, IL).

\section{RESULTS}

All mice included in this study were hindlimb denervated by sciatic nerve resection, which leaves the lower part of the hindlimb unable to contract. The contralateral sham-operated muscle served as the control. There was a main effect of denervation and expression of CaMKIV. Denervation in wildtype control mice resulted in a $68 \%$ decrease in GLUT4 mRNA in the plantaris muscle, and CaMKIV expression increased the amount of GLUT4 mRNA by $30 \%$ in the control muscle of transgenic mice (CaMK IV-TG Cont) compared with control muscle of wild-type mice (WT Cont) (Fig. 1). While expression of CaMK IV did not protect against the typical denervation response, as GLUT4 mRNA decreased by $54 \%(P=5 \times$ $10^{-5}$ ) in denervated muscle, expression of CaMK IV in denervated muscle was sufficient to cause GLUT4 mRNA to be $87 \%$ higher in transgenic vs. wild-type mice $(P=0.02)$.

The mechanism responsible for depressed GLUT4 expression is decreased gene transcription. Because binding of GEF and MEF2 to their respective binding domains on the GLUT4 promoter is necessary for normal GLUT4 transcriptional regulation (33), we tested the activity of GEF and MEF2 in denervated skeletal muscle by performing EMSAs to determine binding of GEF and MEF2 to their respective binding domains in the GLUT4 promoter region in gastrocnemius muscle. EMSAs for MEF2 and GEF were followed up by measuring nuclear and whole tissue (total) GEF and MEF2 protein in gastrocnemius muscle by Western blot analysis.

EMSAs were performed to determine whether GEF binding changed after denervation. GEF binding decreased after denervation by $50 \%(P<0.05)$ compared with GEF binding to Domain 1 in control muscles (Fig. 2). The nuclear and whole

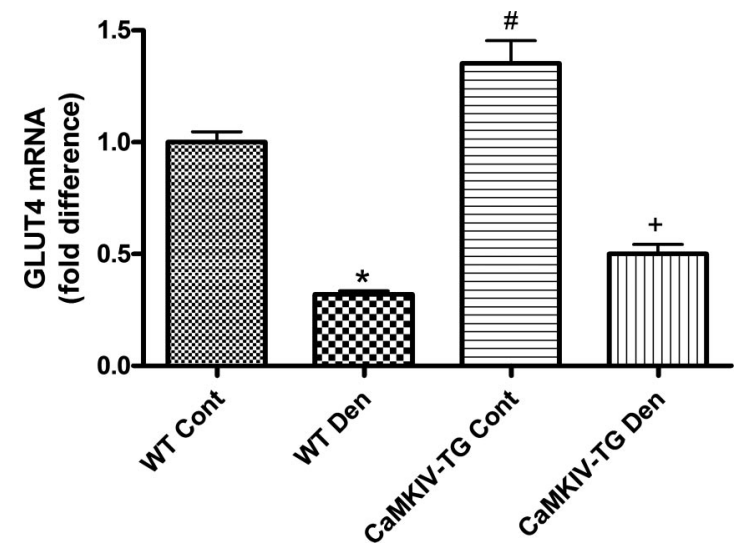

Fig. 1. The effect of denervation on GLUT4 content in plantaris muscle of wild-type mice and mice expressing constitutively active CaMKIV (CaMKIVTG). All GLUT4 mRNA values were normalized to the average GLUT4 mRNA value for the nondenervated wild-type control group. There was a main effect of denervation $\left(P=6 \times 10^{-11}\right)$ and a main effect of transgene $(P=$ 0.0002 ) but no significant interaction. ${ }^{*} P=2 \times 10^{-14}$ for the comparison between nondenervated wild types and denervated wild types. $\# P=0.02$ for the comparison between nondenervated wild-type and nondenervated transgenic mice. $+P=5 \times 10^{-5}$ for the comparison between control and denervated CaMK IV transgenic mice. $n=22$ for both wild-type mice groups. $n=18$ for the nondenervated CaMKIV transgenic group. $n=15$ for denervated transgenic mice. 
A

GEF Binding in Muscle

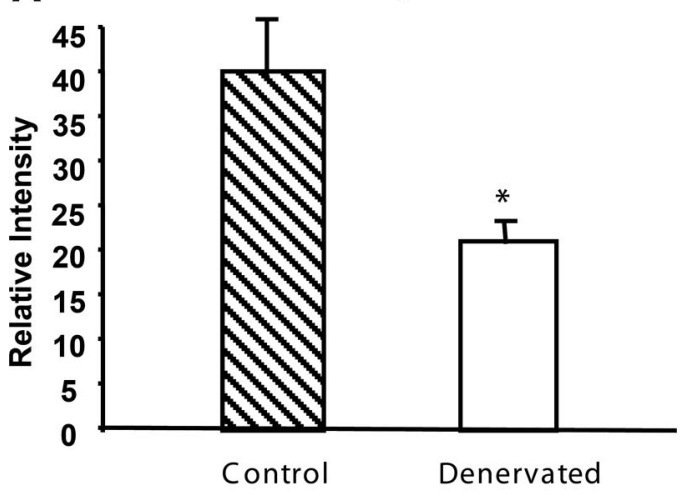

B

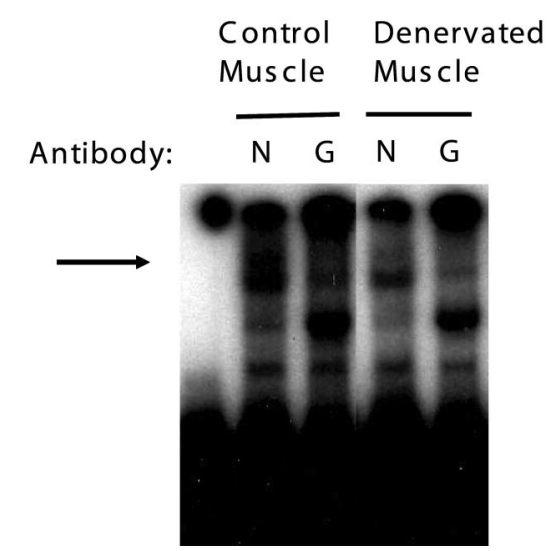

Fig. 2. The effect of denervation on GLUT4 enhancer factor (GEF) binding to domain I in gastrocnemius muscle. A: cmparison of GEF binding to the GLUT4 promoter in control and denervated gastrocnemius. $B$ : representative EMSA gel from this experiment. N, nonimmune antibody; G, GEF antibody. $* P<0.05$ for the comparison between control and denervated samples. $n=$ 6 per group.

cell content levels of GEF after denervation in wild-type mice were then determined. Surprisingly, we found that denervation had no effect on nuclear GEF content (Fig. 3A), but GEF content in the whole tissue lysates (Fig. $3 B$ ) showed a strong trend for a $42 \%$ decrease $(P=0.077)$.

To investigate the role of MEF2 in the regulation of GLUT4 in response to denervation, MEF2A/D levels were measured in the nuclear and whole tissue protein extracts in the gastrocnemius after denervation. Nuclear content of MEF2A/D showed a strong trend toward being higher (129\% increase; $P=0.079$ ) in denervated muscle compared with control muscle (Fig. 4A) and total MEF2A/D protein was $125 \%$ more abundant $(P=$ 0.03 ) in denervated muscle compared with control (Fig. $4 B$ ).

To determine the ability of MEF2 to stimulate transcription, transgenic mice developed to demonstrate activation of MEF2 activity were also denervated. These mice express a lacZ reporter gene controlled by a synthetic promoter containing three repeats of the MEF2 binding site (Fig. 5A). Measurement of $\beta$-galactosidase mRNA, the lac $Z$ gene product, in gastrocnemius muscle by QRT-PCR after $72 \mathrm{~h}$ of denervation showed that there was no change in expression of the reporter gene after denervation (Fig. 5B). EMSA analysis was performed to test for MEF2 binding to the GLUT4 promoter in denervated
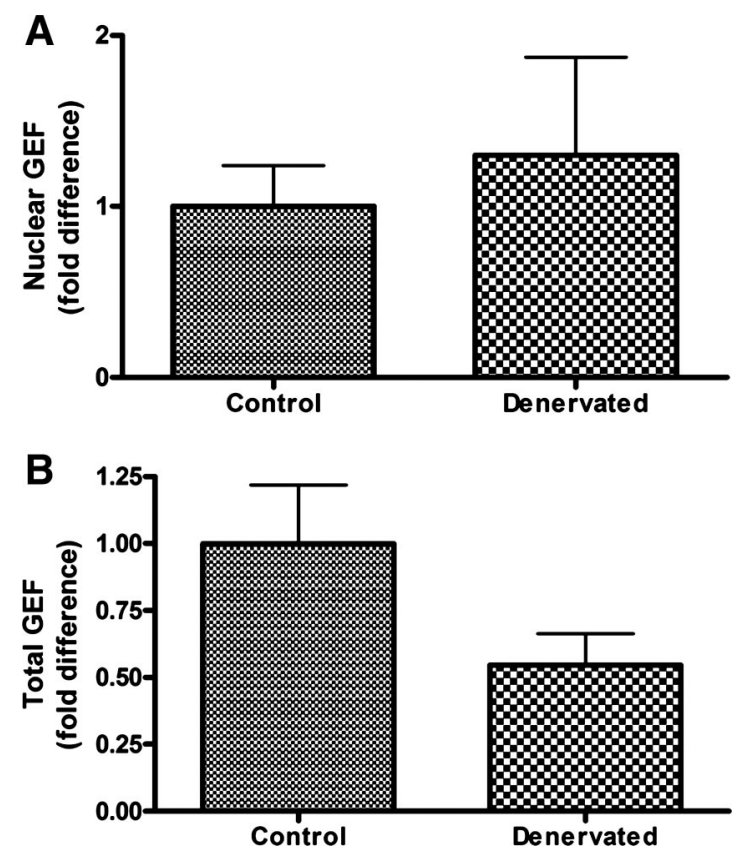

Fig. 3. The effect of denervation on nuclear $(A)$ and GEF whole cell $(B)$ content in gastrocnemius muscle. GEF levels were normalized to the average value for nondenervated muscle. For $A, n=5$ per group; for $B, n=9$ per group.

gastrocnemius. EMSA analysis showed no change in MEF2 binding to the GLUT4 promoter in denervated vs. nondenervated muscle (Fig. 5C). These data both suggest that the ability of MEF2 to stimulate transcription is not impaired by denervation.

Another approach to investigate transcriptional regulation is to determine the DNA sequences of the promoter that are required for the denervation response. Using mice with reporter gene constructs expressing the CAT reporter gene con-
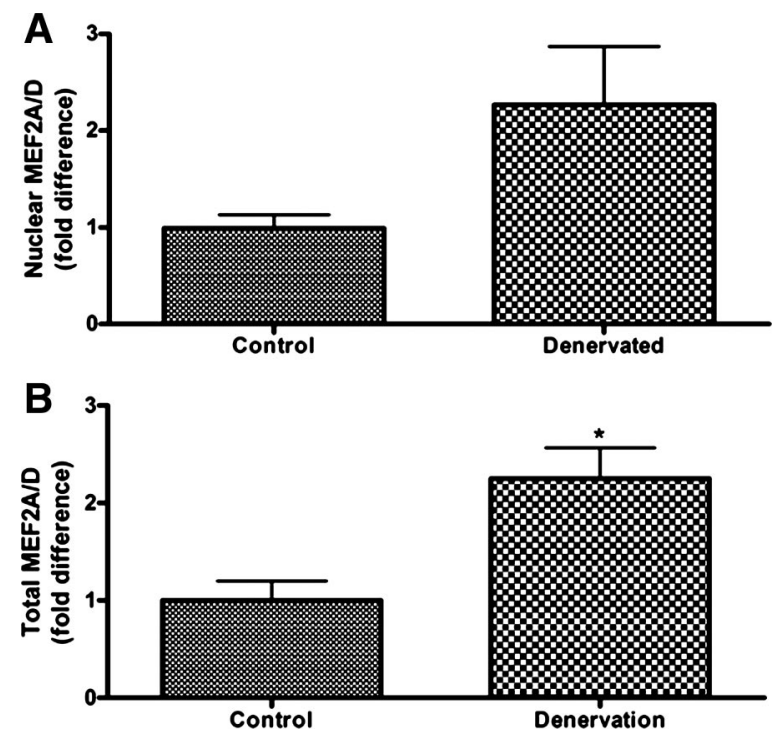

Fig. 4. The effect of denervation on nuclear $(A)$ and whole cell $(B)$ MEF2A/D content in denervated gastrocnemius muscle. Nuclear MEF2 values were normalized to the average value of nuclear MEF2 protein in nondenervated muscle. For $A, n=8$ per group. For $B, * P=0.03$ for the comparison between the control and denervated group; $n=9$ per group. 
A

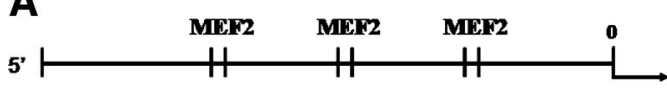

Fig. 5. The effect of denervation on MEF2 activity in denervated gastrocnemius muscle. A: schematic of the synthetic MEF2-rich promoter controlling expression of the lacZ reporter gene. $B$ : expression of the MEF2dependent reporter gene, mRNA $(n=7$ per group). $C$ : representative EMSA for MEF2 binding to the GLUT4 promoter in denervated and control tissue.

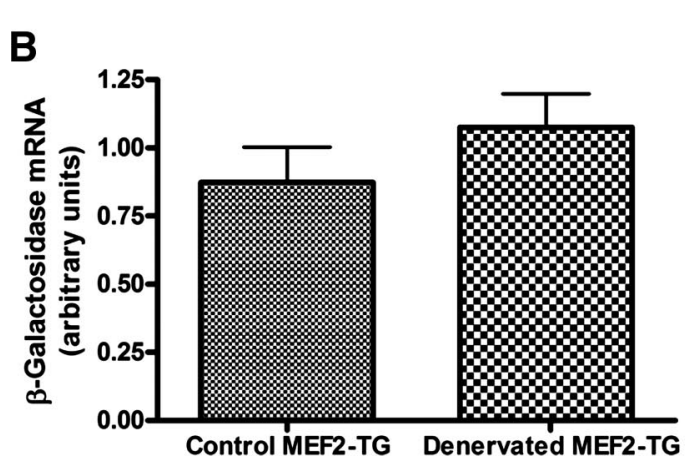

C
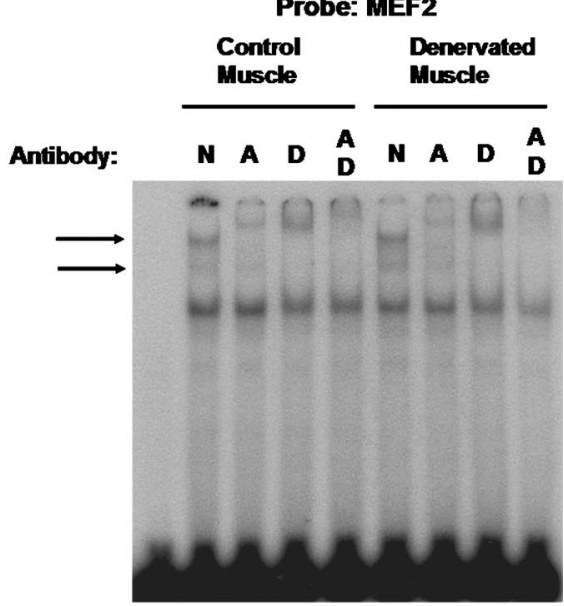

trolled by segments of the hGLUT4 promoter of different lengths, our laboratory has shown that there are no denervation-responsive elements above -895 bp from the transcription initiation site. To further understand what elements may be responsible for the large decrease in GLUT4 expression after denervation, hGLUT4-CAT reporter mice were used again to identify areas of the promoter that negatively influence GLUT4 in response to denervation. Mice were denervated and, after
$72 \mathrm{~h}$, gastrocnemius muscles were removed, and mRNA was isolated and prepared for measurement of CAT mRNA by QRT-PCR or RPA.

Mice with 895 bp of the hGLUT4 promoter controlling expression of the CAT reporter gene were denervated and mRNA was isolated from the gastrocnemius. CAT mRNA was measured by RPA and was found to be decreased by $57 \%(P=$ 0.03 ) in denervated muscle compared with controls (Fig. 6A).
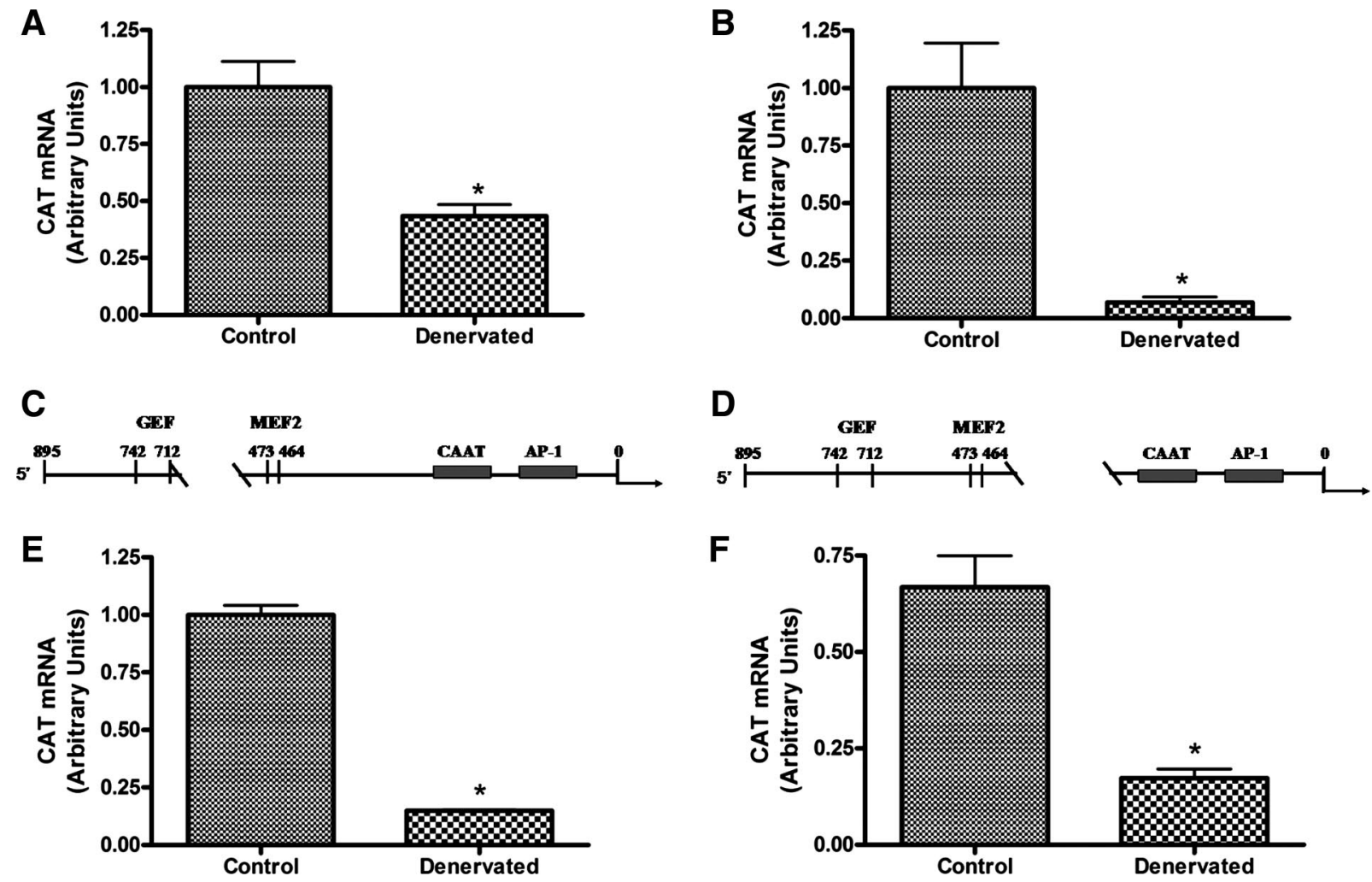

F

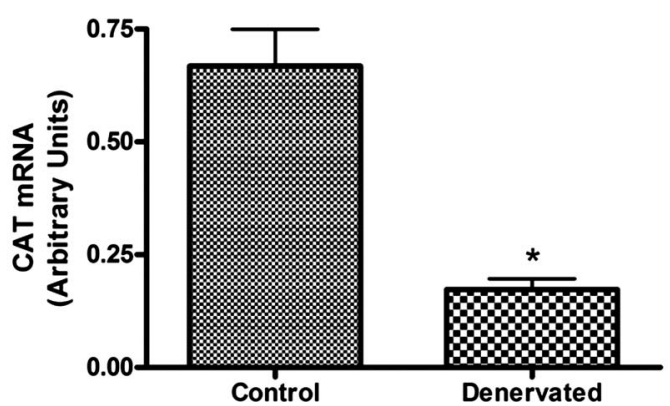

Fig. 6. The effect of denervation on CAT mRNA expression in gastrocnemius muscle of mice expressing the CAT reporter gene controlled by the following lengths of hGLUT4 promoter: $895 \mathrm{bp}(A), 730 \mathrm{bp}(B), 895 \mathrm{bp}$ with a deletion between the GEF and MEF2 binding sites $(D)$, and 895 bp with a deletion between the MEF2 binding site and the basal promoter $(F)$. CAT mRNA content values were normalized to the average for the control group. $A: * P=0.03$ for the comparison between nondenervated control muscles and denervated muscles. $n=4$ mice per group. $B$ : $* P=0.01$ for the comparison of the control and denervated muscle groups. $n=4$ mice per group. $C$ : schematic representing the general architecture of the hGLUT4 promoter driving CAT expression. $D$ : $* P=$ $4 \times 10^{-5}$ for the comparison between control and denervated muscles. $n=5$ mice per group. $E$ : schematic of the promoter controlling CAT expression in these mice. $F: * P=0.0001$ for the comparison of mRNA level between the control and denervated groups; $n=5$ mice per group. 
When mice with $730 \mathrm{bp}$ of hGLUT4 promoter were denervated and mRNA from the plantaris was measured by QRT-PCR, CAT reporter expression was found to be decreased by $93 \%$ $(P=0.01)$ (Fig. $6 B)$. This result demonstrates that the denervation responsive element is within the first 730 base pairs of the GLUT4 promoter. Because the GEF binding domain, Domain I, is disrupted in the 730 bp mice, the normal denervation response in muscle with this reporter construct indicates that the decrease in GLUT4 expression does not require that Domain I be intact.

Because deletion of the MEF2 or the GEF site results in loss of GLUT4 expression, we turned to two lines of mice that had $895 \mathrm{bp}$ of the hGLUT4 promoter but with large deleted sections between known vital elements. The first of these new GLUT4-reporter mice has a deletion between bases -711 and -526 (Fig. 6C). These mice were denervated, and CAT reporter mRNA from the gastrocnemius was measured by RPA (Fig. 6D). Denervation decreased the amount of CAT mRNA in the gastrocnemius by $85 \%\left(P=4 \times 10^{-5}\right)$. This demonstrates that the denervation responsive element does not likely exist between the MEF2 and GEF binding domains.

Another similar group of mice with the typical $895 \mathrm{bp}$ GLUT4 promoter but with a deleted region between bases -220 and -440 was denervated (Fig. 6E). CAT reporter mRNA was measured from the gastrocnemius muscle of these mice by QRT-PCR, and they were found to have an $80 \%$ decrease in CAT mRNA $(P=0.0001)$ (Fig. 6F). This result shows that the denervation response element is not likely within the promoter region between the MEF2 binding domain and the basal promoter.

\section{DISCUSSION}

The experiments of this study were designed to test the hypothesis that decreased GLUT4 expression in denervated skeletal muscle is due to depressed activity of CaMK, which then leads to decreased activation of the transcription factors MEF2 and GEF. To test the role of CaMK signaling in regulation of GLUT4 expression in denervated muscle, GLUT4 mRNA was measured in wild-type mice and mice expressing constitutively active CaMKIV. Normal CaMK signaling may not be accurately restored by expressing a constitutively active CaMK to make up for the loss of signaling through the diminished sporadically activated CaMK. However, we felt a loss of GLUT4 expression in denervated mice, with presumptively lower CaMK signaling, and an increase in GLUT4 in a mouse with constitutively active CaMK still made investigating the expression of GLUT4 in a denervated CaMK-transgenic mouse interesting for the purpose of determining whether increased CaMK signaling could attenuate the loss of GLUT4 expression in denervated muscle.

CaMKIV is not expressed in skeletal muscle and the major CaMK isoform in human and rodent muscle is CaMKII $(1,36$, 37). CaMKII becomes active when bound by calcium/calmodulin and maintains its activity through autophosphorylation. Phosphorylation of CaMKII causes it to move to the nucleus. CaMKIV is typically located in the nucleus and becomes activated by calcium/calmodulin and by phosphorylation by CaMKK (39). We believe that CaMKIV may be a suitable surrogate for CaMKII because 1) CaMKII and CaMKIV share many common substrates, such as MEF2A and class II HDAC proteins, which seem likely to regulate MEF2 action, and thus GLUT4 expression $(24,27), 2)$ CaMKIV has been shown to be functional in skeletal muscle after it is expressed (46), 3) CaMKII is a large heteromeric protein, which because of its complexity, is much more difficult to study than the monomeric CaMKIV overexpression models (14). For this reason, we feel that mice that express constitutively active CaMKIV are good candidates for study of CaMK signaling in muscle (14), particularly in the study of GLUT4.

We expect that, had we been able to study mice with activated CaMKII, the results would have been similar to those observed in the CaMKIV model. CaMKII and CaMKIV share many common substrates, such as MEF2A and class II HDAC proteins, which seem likely to regulate MEF2 action, and thus GLUT4 expression $(24,27)$. In humans, one acute bout of exercise increased promoter binding of MEF2. MEF2A increased in the nucleus, but MEF2D did not (25). After one bout of acute swimming in rats, MEF2A binding to the GLUT4 promoter was increased. In CaMKIV-transgenic mice, ChIP assays were done to show that MEF2A binding to the GLUT4 promoter was increased. This study showed also that CaMKIV and CaMKII have MEF2A as a common substrate (40).

In other experiments, when we exercise trained these mice on a running wheel for $2 \mathrm{wk}$, there was a significant increase in GLUT4 in wild-type mice. CaMK-transgenic mice, however, had no increase in the amount of GLUT4 mRNA or protein in response to exercise. This suggests that $\mathrm{CaMK}$ stimulation in trained muscle plays a prominent role, since regulation by a pathway different than CaMK would be expected to generate an additive increase in GLUT4 content in exercised CaMKtransgenic mice. The results of this study provide evidence that CaMKIV activates the same signals as CaMKII and that these CaMK-dependent signals are of major importance in regulating GLUT4 expression. If CaMKIV and CaMKII had separate signaling pathways, then transgenic expression of CaMKIV and exercise would have had additive effects.

Control muscle of CaMK-transgenic mice had significantly more GLUT4 mRNA than control muscle of wild-type mice, but CaMKIV expression was not able to maintain GLUT4 expression levels in denervated muscle. Although there was a significant decline in GLUT4 mRNA content after denervation, there was significantly more GLUT4 in muscle of denervated CaMK-transgenic mice compared with wild-type mice. This is similar to previous work in our lab with AMPK (9). AMPK activation by AICAR administration was sufficient to increase the expression of GLUT4 in muscle, but AMPK was not able to maintain GLUT4 content when challenged with denervation.

The increase in muscle GLUT4 content in exercised muscle is thought to result from increased activity of CaMK (unpublished data) and AMPK (reviewed in Ref. 45), although AMPK has been shown not to be required for the GLUT4 exercise response to occur (9). Supporting our hypothesis that CaMK causes increased production of GLUT4 after exercise is the finding that HDAC5, a CAMK-responsive transcriptional corepressor, inhibits GLUT4 expression (26), and the finding that, similar to exercise, CaMK increases the binding of MEF2A to the GLUT4 promoter. Although CaMK may mediate the exercise response of GLUT4, this study, in which mice expressing constitutively active CaMK had typical decreases in GLUT4 after denervation, has proven that the main cause for decreased GLUT4 content in denervated muscle is not de- 
creased activity of CaMK. Megeney et al. (28) compared the difference in GLUT4 response to denervation and muscle inactivity. Glucose transport was decreased to the same extent in denervated muscles and muscles rendered noncontractile, but with the motor nerve still intact, by TTX superfusion of the sciatic nerve. However, GLUT4 content was decreased to a much greater extent in denervated muscles compared with TTX-treated muscles (28). These data indicated that denervation is a mixed model of muscle inactivity and elimination of neural signaling and delivery of neural trophic factors to the nerve, with the elimination of neural effects having a more profound role on GLUT4 content than muscle inactivity.

Having found that loss of CaMK signaling does not mediate the decrease in GLUT4 in denervated muscles, we investigated the content and activity of the putative GLUT4 transcription factors GEF and MEF2 to determine whether signaling regulating GLUT4 was mediated by GEF and MEF2. Binding of both GEF and MEF2 to their respective binding domains on the GLUT4 promoter is necessary for normal GLUT4 transcriptional regulation. EMSAs were performed to determine binding of GEF and MEF2 to their respective binding domains in the GLUT4 gene promoter. In addition, nuclear and whole tissue (total) GEF and MEF2 protein were determined by Western blot analysis. EMSAs suggested there was no change in MEF2 binding to the GLUT4 promoter. MEF2A/D protein tended to increase with denervation as denervated muscle had significantly higher total MEF2A/D and a trend $(P=0.08)$ for increased nuclear MEF2A/D protein. The lack of change in MEF2 binding and no change in MEF2 protein in the nucleus are consistent with a lack of change in nuclear HDAC5 (unpublished data) content in nuclei from denervated gastrocnemius.

The lack of regulation of MEF2 in denervation is also demonstrated by the results of an experiment with mice expressing an MEF2-dependent lacZ reporter gene. Reporter gene expression did not decrease after denervation, as it would have if MEF2 had taken on an inhibitory role in the denervated state. These MEF2 reporter mice have been used in the past to show that MEF2 transcription-enhancing activity increased in contracting muscle (48). The fact that these mice have been used to successfully show that MEF2 activity increases with muscle contraction seems to support our conclusion that the decrease in GLUT4 expression in denervated muscle is not due to decreased MEF2 activity, as indicated by the lack of decreased reporter gene expression in denervated muscle.

GEF binding to Domain I was measured and found to be decreased by $50 \%$ after denervation. Further evidence for decreased GEF activity was the finding that total GEF protein showed a similar trend $(P=0.07)$ with average total GEF $42 \%$ lower in denervated than in control tissue. However, the hypothesis that decreased GEF activation causes GLUT4 expression to be depressed seems unlikely given that hGLUT4/ CAT reporter mice with $730 \mathrm{bp}$ of GLUT4 promoter responded normally to denervation. With the position of Domain I being from $-742 \mathrm{bp}$ to $-712 \mathrm{bp}$ in the GLUT4 promoter, it is truncated in the mice with $730 \mathrm{bp}$ of promoter, and this disrupts GEF binding. Intact Domain I is required for hormonal regulation, while complete deletion of Domain I abrogates GLUT4 expression. The truncated Domain I contained in the mice with $730 \mathrm{bp}$ of promoter allows for basal GLUT4 regulation, but if signaling through GEF were responsible for decreased GLUT4 expression, then we would have expected that an intact Domain I would have to be present for proper repression of CAT reporter expression in response to denervation. Therefore, decreased GEF stimulation through the truncated Domain I may have played a role in the decline in expression of GLUT4.

To study GLUT4 regulation at the promoter, we focused on the regions that lie between Domain I and the MEF2 binding site and between the MEF2 binding site and the basal promoter. The combined effect of the battery of GLUT4/CAT reporter mice denervated was the deletion or mutation of nearly all of the GLUT4 promoter except for the MEF2 binding domain and the basal promoter. CAT reporter gene expression following denervation was significantly decreased in all transgenic lines. These data along with the fact that MEF2 was rejected as acting as an inhibitor to GLUT4 expression in denervated muscle due to the normal expression of the lac $Z$ reporter gene in the MEF2-reporter mice led us to conclude that the denervation-induced decrease in GLUT4 gene expression is mediated through the truncated Domain I or the basal promoter region of the GLUT4 gene.

Previous data from our lab showed, similar to our findings with CaMK, that GLUT4 content does not decrease in denervated muscle due to a reduction in AMPK activity. However, mice with increased AMPK activity, due to AICAR treatment, had greater GLUT4 content after denervation than untreated controls. This finding is similar to our findings with $\mathrm{CaMK}$ in that mice expressing constitutively active CaMK IV had more GLUT4 after denervation than did denervated wild-type mice. Keeping in mind, as Megeney et al. (28) demonstrated, that denervation is a model of both muscle inactivity and abrogated neural signaling, we believe that these results demonstrate the ability of AMPK and CaMK to recover the loss of GLUT4 production due to muscle inactivity, but not the loss of GLUT4 due to decreased neural signaling and delivery of neural trophic factors. To elucidate this ability, future studies measuring GLUT4 in an innervated, but inactive, muscle expressing constitutively active CaMK or treated with AICAR should be performed.

In summary, the results of this study suggest that decreased CaMK activity does seem to be responsible for the portion of GLUT4 lost due to muscle inactivity, but more work will need to be done to determine the effectiveness of CaMK as a treatment for inactivity-induced reduction of GLUT4 content. Regulation by MEF2 does not seem to be involved in the denervation-induced loss of GLUT4 in muscle, while a role for GEF seems doubtful but cannot be ruled out yet. The effects, on GLUT4, of the decreased neural signaling are mainly mediated by factors other than CaMK, MEF2, and GEF. The decrease in GLUT4 in denervated muscle appears to be largely regulated by altered signaling at the basal promoter of the GLUT4 gene.

\section{GRANTS}

The project was supported by a grant from the NIH (R01 DK046121 to L. Dohm) and from the Gatorade Sport Science Institute (to E. Jensen).

\section{REFERENCES}

1. Akimoto T, Ribar TJ, Williams RS, Yan Z. Skeletal muscle adaptation in response to voluntary running in $\mathrm{Ca}^{2+} /$ calmodulin-dependent protein kinase IV-deficient mice. Am J Physiol Cell Physiol 287: C1311-C1319, 2004. 
2. Block NE, Menick DR, Robinson KA, Buse MG. Effect of denervation on the expression of two glucose transporter isoforms in rat hindlimb muscle. J Clin Invest 88: 1546-1552, 1991.

3. Brozinick JT Jr, McCoid SC, Reynolds TH, Nardone NA, Hargrove DM, Stevenson RW, Cushman SW, Gibbs EM. GLUT4 overexpression in $d b / d b$ mice dose-dependently ameliorates diabetes but is not a lifelong cure. Diabetes 50: 593-600, 2001.

4. Coderre L, Monfar MM, Chen KS, Heydrick SJ, Kurowski TG, Ruderman NB, Pilch PF. Alteration in the expression of GLUT-1 and GLUT-4 protein and messenger RNA levels in denervated rat muscles. Endocrinology 131: 1821-1825, 1992.

5. Eriksson J, Koranyi L, Bourey R, Schalin-Jantti C, Widen E, Mueckler M, Permutt AM, Groop LC. Insulin resistance in type 2 (non-insulindependent) diabetic patients and their relatives is not associated with a defect in the expression of the insulin-responsive glucose transporter (GLUT-4) gene in human skeletal muscle. Diabetologia 35: 143-147, 1992.

6. Ezaki O. Regulatory elements in the insulin-responsive glucose transporter (GLUT4) gene. Biochem Biophys Res Commun 241: 1-6, 1997.

7. Gibbs EM, Stock JL, McCoid SC, Stukenbrok HA, Pessin JE, Stevenson RW, Milici AJ, McNeish JD. Glycemic improvement in diabetic $d b / d b$ mice by overexpression of the human insulin-regulatable glucose transporter (GLUT4). J Clin Invest 95: 1512-1518, 1995.

8. Grozinger CM, Schreiber SL. Regulation of histone deacetylase 4 and 5 and transcriptional activity by 14-3-3-dependent cellular localization. Proc Natl Acad Sci USA 97: 7835-7840, 2000.

9. Holmes BF, Lang DB, Birnbaum MJ, Mu J, Dohm GL. AMP kinase is not required for the GLUT4 response to exercise and denervation in skeletal muscle. Am J Physiol Endocrinol Metab 287: E739-E743, 2004.

10. Houmard JA, Egan PC, Neufer PD, Friedman JE, Wheeler WS, Israel RG, Dohm GL. Elevated skeletal muscle glucose transporter levels in exercise-trained middle-aged men. Am J Physiol Endocrinol Metab 261: E437-E443, 1991.

11. Houmard JA, Hickey MS, Tyndall GL, Gavigan KE, Dohm GL. Seven days of exercise increase GLUT-4 protein content in human skeletal muscle. J Appl Physiol 79: 1936-1938, 1995.

12. Houmard JA, Hortobagyi T, Neufer PD, Johns RA, Fraser DD, Israel RG, Dohm GL. Training cessation does not alter GLUT-4 protein levels in human skeletal muscle. J Appl Physiol 74: 776-781, 1993.

13. Houmard JA, Weidner MD, Dolan PL, Leggett-Frazier N, Gavigan KE, Hickey MS, Tyndall GL, Zheng D, Alshami A, Dohm GL. Skeletal muscle GLUT4 protein concentration and aging in humans. Diabetes 44: 555-560, 1995.

14. Hudmon A, Schulman H. Neuronal $\mathrm{CA}^{2+} /$ calmodulin-dependent protein kinase II: the role of structure and autoregulation in cellular function. Annu Rev Biochem 71: 473-510, 2002.

15. Ikemoto S, Thompson KS, Takahashi M, Itakura H, Lane MD, Ezaki O. High fat diet-induced hyperglycemia: prevention by low level expression of a glucose transporter (GLUT4) minigene in transgenic mice. Proc Natl Acad Sci USA 92: 3096-3099, 1995.

16. Ishizuka T, Klepcyk P, Liu S, Panko L, Gibbs EM, Friedman JE. Effects of overexpression of human GLUT4 gene on maternal diabetes and fetal growth in spontaneous gestational diabetic C57BLKS/J Lepr(db/+) mice. Diabetes 48: 1061-1069, 1999.

17. Jones JP, Dohm GL. Regulation of glucose transporter GLUT-4 and hexokinase II gene transcription by insulin and epinephrine. Am J Physiol Endocrinol Metab 273: E682-E687, 1997.

18. Jones JP, Tapscott EB, Olson AL, Pessin JE, Dohm GL. Regulation of glucose transporters GLUT-4 and GLUT-1 gene transcription in denervated skeletal muscle. J Appl Physiol 84: 1661-1666, 1998.

19. Katz EB, Burcelin R, Tsao TS, Stenbit AE, Charron MJ. The metabolic consequences of altered glucose transporter expression in transgenic mice. J Mol Med 74: 639-652, 1996.

20. Koranyi LI, Bourey RE, Vuorinen-Markkola H, Koivisto VA, Mueckler M, Permutt MA, Yki-Jarvinen H. Level of skeletal muscle glucose transporter protein correlates with insulin-stimulated whole body glucose disposal in man. Diabetologia 34: 763-765, 1991.

21. Leturque A, Loizeau M, Vaulont S, Salminen M, Girard J. Improvement of insulin action in diabetic transgenic mice selectively overexpressing GLUT4 in skeletal muscle. Diabetes 45: 23-27, 1996.

22. Liu ML, Olson AL, Edgington NP, Moye-Rowley WS, Pessin JE. Myocyte enhancer factor 2 (MEF2) binding site is essential for C2C12 myotube-specific expression of the rat GLUT4/muscle-adipose facili- tative glucose transporter gene. J Biol Chem 269: 28514-28521, 1994.

23. Liu ML, Olson AL, Moye-Rowley WS, Buse JB, Bell GI, Pessin JE. Expression and regulation of the human GLUT4/muscle-fat facilitative glucose transporter gene in transgenic mice. J Biol Chem 267: $11673-$ 11676, 1992.

24. Liu Y, Randall WR, Schneider MF. Activity-dependent and -independent nuclear fluxes of HDAC4 mediated by different kinases in adult skeletal muscle. J Cell Biol 168: 887-897, 2005.

25. McGee SL, Sparling D, Olson AL, Hargreaves M. Exercise increases MEF2- and GEF DNA-binding activity in human skeletal muscle. FASEB J 20: 348-349, 2006.

26. McGee SL, van Denderen BJ, Howlett KF, Mollica J, Schertzer JD, Kemp BE, Hargreaves M. AMP-activated protein kinase regulates GLUT4 transcription by phosphorylating histone deacetylase 5. Diabetes 57: 860-867, 2008.

27. McKinsey TA, Zhang CL, Lu J, Olson EN. Signal-dependent nuclear export of a histone deacetylase regulates muscle differentiation. Nature 408: 106-111, 2000.

28. Megeney LA, Michel RN, Boudreau CS, Fernando PK, Prasad M, Tan MH, Bonen A. Regulation of muscle glucose transport and GLUT-4 by nerve-derived factors and activity-related processes. Am J Physiol Regul Integr Comp Physiol 269: R1148-R1153, 1995.

29. Megeney LA, Neufer PD, Dohm GL, Tan MH, Blewett CA, Elder GC, Bonen A. Effects of muscle activity and fiber composition on glucose transport and GLUT-4. Am J Physiol Endocrinol Metab 264: E583-E593, 1993.

30. Muoio DM, Way JM, Tanner CJ, Winegar DA, Kliewer SA, Houmard JA, Kraus WE, Dohm GL. Peroxisome proliferator-activated receptoralpha regulates fatty acid utilization in primary human skeletal muscle cells. Diabetes 51: 901-909, 2002.

31. Naya FJ, Wu C, Richardson JA, Overbeek P, Olson EN. Transcriptional activity of MEF2 during mouse embryogenesis monitored with a MEF2-dependent transgene. Development 126: 2045-2052, 1999.

32. Olson AL, Pessin JE. Transcriptional regulation of the human GLUT4 gene promoter in diabetic transgenic mice. J Biol Chem 270: 2349123495, 1995.

33. Oshel KM, Knight JB, Cao KT, Thai MV, Olson AL. Identification of a 30-base pair regulatory element and novel DNA binding protein that regulates the human GLUT4 promoter in transgenic mice. $J$ Biol Chem 275: 23666-23673, 2000.

34. Passier R, Zeng H, Frey N, Naya FJ, Nicol RL, McKinsey TA, Overbeek P, Richardson JA, Grant SR, Olson EN. CaM kinase signaling induces cardiac hypertrophy and activates the MEF2 transcription factor in vivo. J Clin Invest 105: 1395-1406, 2000.

35. Ren JM, Marshall BA, Mueckler MM, McCaleb M, Amatruda JM, Shulman GI. Overexpression of Glut4 protein in muscle increases basal and insulin-stimulated whole body glucose disposal in conscious mice. J Clin Invest 95: 429-432, 1995.

36. Rose AJ, Hargreaves M. Exercise increases $\mathrm{Ca}^{2+}$-calmodulin-dependent protein kinase II activity in human skeletal muscle. J Physiol 553: 303-309, 2003.

37. Rose AJ, Kiens B, Richter EA. $\mathrm{Ca}^{2+}$-calmodulin-dependent protein kinase expression and signalling in skeletal muscle during exercise. J Physiol 574: 889-903, 2006.

38. Santalucia T, Moreno H, Palacin M, Yacoub MH, Brand NJ, Zorzano A. A novel functional co-operation between MyoD, MEF2 and TR $\alpha 1$ is sufficient for the induction of GLUT4 gene transcription. J Mol Biol 314: 195-204, 2001.

39. Sigma-Aldrich. Calcium and Calmodulin-Dependent Protein Kinases Overview. St. Louis, MO: Sigma-Aldrich (Online).

40. Smith JA, Collins M, Grobler LA, Magee CJ, Ojuka EO. Exercise and CaMK activation both increase the binding of MEF2A to the GLUT4 promoter in skeletal muscle in vivo. Am J Physiol Endocrinol Metab 292: E413-E420, 2007.

41. Thai MV, Guruswamy S, Cao KT, Pessin JE, Olson AL. Myocyte enhancer factor 2 (MEF2)-binding site is required for GLUT4 gene expression in transgenic mice. Regulation of MEF2 DNA binding activity in insulin-deficient diabetes. J Biol Chem 273: 14285-14292, 1998.

42. Treadway JL, Hargrove DM, Nardone NA, McPherson RK, Russo JF, Milici AJ, Stukenbrok HA, Gibbs EM, Stevenson RW, Pessin JE. Enhanced peripheral glucose utilization in transgenic mice expressing the human GLUT4 gene. J Biol Chem 269: 29956-29961, 1994. 
43. Tsao TS, Burcelin R, Katz EB, Huang L, Charron MJ. Enhanced insulin action due to targeted GLUT4 overexpression exclusively in muscle. Diabetes 45: 28-36, 1996.

44. Wang AH, Kruhlak MJ, Wu J, Bertos NR, Vezmar M, Posner BI, Bazett-Jones DP, Yang XJ. Regulation of histone deacetylase 4 by binding of 14-3-3 proteins. Mol Cell Biol 20: 6904-6912, 2000.

45. Winder WW, Taylor EB, Thomson DM. Role of AMP-activated protein kinase in the molecular adaptation to endurance exercise. Med Sci Sports Exerc 38: 1945-1949, 2006.

46. Wu H, Kanatous SB, Thurmond FA, Gallardo T, Isotani E, BasselDuby R, Williams RS. Regulation of mitochondrial biogenesis in skeletal muscle by CaMK. Science 296: 349-352, 2002.
47. Wu H, Naya FJ, McKinsey TA, Mercer B, Shelton JM, Chin ER, Simard AR, Michel RN, Bassel-Duby R, Olson EN, Williams RS. MEF2 responds to multiple calcium-regulated signals in the control of skeletal muscle fiber type. EMBO J 19: 1963-1973, 2000.

48. Wu H, Rothermel B, Kanatous S, Rosenberg P, Naya FJ, Shelton JM, Hutcheson KA, DiMaio JM, Olson EN, Bassel-Duby R, Williams RS. Activation of MEF2 by muscle activity is mediated through a calcineurin- dependent pathway. EMBO J 20: 6414-6423, 2001.

49. Zorzano A, Santalucia T, Palacin M, Guma A, Camps M. Searching for ways to upregulate GLUT4 glucose transporter expression in muscle. Gen Pharmacol 31: 705-713, 1998.

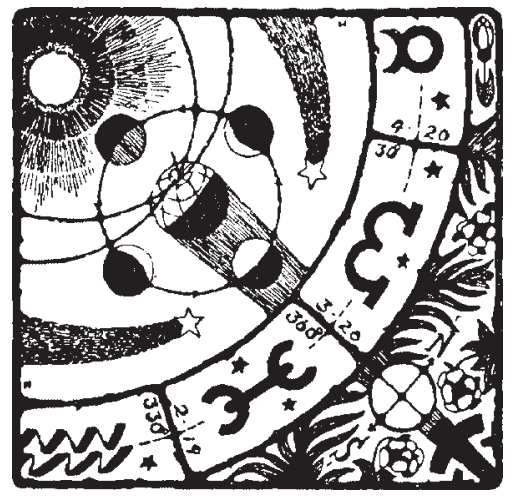

